\title{
Heterogeneity in consumer preferences for ready-to-eat pomegranate: an empirical study in Italy
}

\author{
Alice Stiletto, Elisa Giampietri and Samuele Trestini \\ Department of TeSAF, University of Padova, Padova, Italy
}

\begin{abstract}
Purpose - The present study aims at analysing consumer preferences for the pomegranate fruit, focussing on the effect of ready-to-eat format (i.e. packaged arils) on the purchasing choice, together with several products' attributes as the origin, the packaging typology and the price.

Design/methodology/approach - The paper presents a choice experiment (CE) among 626 Italian consumers from Veneto region through an online survey. The study estimates both a conditional logit (CL) and a latent class logit model (LCM).

Findings - By segmenting the sample based on the heterogeneous preferences of consumers, it can distinguish "eco-friendly consumers", "time-saving lovers", "nationalists" and "price sensitive" subjects. Interestingly, the marginal willingness to pay for ready-to-eat arils is positive for the "time-saving lovers" that are mainly young consumers. The Italian origin has always a positive effect on the choice, whereas a negative effect is found for the price. Finally, the eco-friendly package has both a negative and a positive effect.

Research limitations/implications - The sample of this study is not representative of the population and the $\mathrm{CE}$ has a hypothetical nature. It follows that further research will link the economic analysis to a consumer test on a more representative sample.

Practical implications - This study can be useful for the pomegranate producers and the industry because it provides original evidence that could drive their business and marketing strategies, for instance, the preference for ready-to-eat arils.

Originality/value - This study is one of the first seeking to determine the factors that affect consumers' preferences for pomegranate arils.
\end{abstract}

Keywords Pomegranate, Arils, Consumer preference, Choice experiment, Willingness to pay, Ready-to-eat, Latent class analysis

Paper type Research paper

\section{Introduction}

In recent years, the pomegranate fruit (Punica granatum $L$.) has attracted a remarkable interest from producers and consumers globally, due to its recognized health benefits (Holland and BarYa'akov, 2008; Karimi et al., 2017). Indeed, from a consumer perspective, the healthiness is recognized as one of the most significant market and innovation drivers in relation to the food and drink industry (Lähteenmäki et al., 2010). As stated by many authors (see, for instance, Gil et al., 2000; Kulkarni et al., 2007; Faria and Calhau, 2011), the spreading success of the pomegranate can be largely explained by its renowned nutraceutical properties (e.g. antiinflammatory, antimicrobial and antioxidant) and, commercially speaking, its diversified consumption patterns and the relative ease of use (e.g. as a fresh fruit or a juice or vinegar).

(C) Alice Stiletto, Elisa Giampietri and Samuele Trestini. Published by Emerald Publishing Limited. This article is published under the Creative Commons Attribution (CC BY 4.0) licence. Anyone may reproduce, distribute, translate and create derivative works of this article (for both commercial and non-commercial purposes), subject to full attribution to the original publication and authors. The full terms of this licence may be seen at http://creativecommons.org/licences/by/4.0/legalcode

This research is linked to the VA_MO Project "Valore Aggiunto Melograno", financed by the Veneto Region's Rural Development Program 2014-2020, measure 16.2.1, linked with EIP-Agri Network.

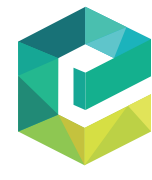

British Food Journal Vol. 122 No. 12,2020 pp. 3869-3884 Emerald Publishing Limited DOI 10.1108/BFJ-08-2019-0655 
$\mathrm{BFJ}$

122,12

3870

It is worth noting that there are no official trade data for pomegranate; however, the most recent available statistics indicate that the class of fruits [1] in which the pomegranate is included (pomegranate being the most important product in this group, according to the experts) has increased its export volumes from 67,000 tonnes in 2013 to 95,000 tonnes in 2017 worldwide, due especially to the market development of Turkey and Peru where it is well adapted. Although global estimates are unavailable, Europe represents a net importer of pomegranates, with an estimated net volume (i.e. import minus export) close to 50,000 tonnes in 2017 and Germany as the most important buyer followed by Italy. On the contrary, developing countries such as Colombia, Peru and South Africa are the most important exporters: from here, fruits arrive in The Netherlands and then are distributed all over Europe. According to a recent paper by Dandachi et al. (2017), among the biggest producers and exporters of pomegranates worldwide, we find Iran, whereas Turkey among the Mediterranean countries and Spain in Western Europe.

Despite the growing interest in this fruit, consumer preferences for pomegranate remain barely investigated by literature. Even though the reasons behind consumer purchase of pomegranate fruit could be different, we assume that its consumption may be linked to its renowned health benefits, in line with the ongoing global drive for a healthier diet. Indeed, nowadays there is a growing consumer demand for convenient and fresh food products, with a high nutritional value and free of additives as minimally fresh processed fruits (Caleb et al., 2012). As regards the pomegranate fruit, this trend is currently pushing producers to propose innovative variants of this traditional fruit as new juice blends, jellies, jams, syrups (CalínSánchez et al., 2011; Martínez et al., 2012; Sidhu and Zafar, 2012; Zaouay et al., 2014; AlcarazMármol et al., 2015; Rios-Corripio and Guerrero-Beltrán, 2019). Furthermore, according to Ana et al. (2007), the demand for ready-to-eat products has increased globally in recent years, due to a general change in the lifestyle of consumers who increasingly look for convenience products even in terms of time saving; indeed, Tallant et al. (2018) show that the availability of convenience foods is a relevant factor to encourage fruit and vegetable consumption. According to Caleb et al. (2012), the still limited pomegranate consumption is also due to consumers' perceived difficulty of extracting the arils from the fruit. To this purpose, readyto-eat arils represent a more appealing innovative product than the whole pomegranate fruit (Ergun and Ergun, 2009), thus representing an interesting prospect for the consumer acceptance and the market development of this fruit.

To the best of our knowledge, except for the study by McAdams et al. (2013), to date there is no other study on consumers' preferences for arils and their willingness to pay (WTP) for this innovative product as for the whole pomegranate fruit, especially in Italy. Hence, the aim of this paper is to investigate consumer preferences and WTP for several pomegranate attributes including arils through a choice experiment among 626 Italian consumers.

\section{Background}

The pomegranate fruit has a long recorded history: being native of Iran, pomegranate became naturalized in many regions of the Mediterranean Basin (Stover and Mercure, 2007). Given its easy growth without special requirements, its high adaptability to harsh conditions and its tolerance of saline and heavy soils with respect to other crops, this long-lived plant may play a role in the valorization of marginal lands (Dandachi et al., 2017). Its commercial appeal among consumers is mainly due to its several health and nutritional properties: among others, its antioxidant (Guo et al., 2007) and antimicrobial activity (Howell and D'Souza, 2013). These properties are due to the large polyphenol content that accounts for at least $3 \%$ of the edible fruit (Al-Maiman and Ahmad, 2002). Although more than 500 known cultivars exist, only dozens are actually cultivated worldwide (Mayuoni-Kirshenbaum et al., 2013) as Wonderful, Bhagwa, Rosh Hapered, Akko, and Mollar De Elche (a PDO of Alicante in Spain). 
Arils, which are separated by a white astringent membrane, represent the edible part of the fruit; they can be directly consumed or transformed to produce juice, jellies, concentrates and so on. Anthocyanins are responsible for their red colour that represents one of the fundamental quality parameters in relation to consumer acceptability of the fruit (Geveke et al., 2013). In addition to quality and sensory characteristics (Mena et al., 2011), consumers' acceptance of healthy products such as pomegranate can be subordinated to its ease of use. Indeed, nowadays convenience represents an important food choice motive (Pula et al., 2014) as the perception of naturalness (Roman et al., 2017). To this purpose, ready-to-eat arils allow to preserve the natural quality of the product, as the shelling process preserves the product genuineness. Nevertheless, it is relevant to note that the edible part cannot be easily separated from the mesocarp and the exocarp (Continella et al., 2018), thus representing an obstacle to the utilization of the fruit. It follows that a commercial product as ready-to-eat arils would be more appealing to consumers than the whole fruit as they considerably reduce the time needed to consume the fruit, while meeting the recent challenge for the food industry to preserve the nutraceutical properties (e.g. minimally processed arils). Accordingly, as stated by Reis et al. (2016), "one of the top trends in the food and beverage market is the intersection of health and convenience". Conceivably, the potential of being transformed in ready-to-eat arils that both preserve the naturalness of the product and represent a convenience product in terms of time saving could optimize consumers' utility and thus potentially increase the pomegranate consumption (Ergun and Ergun, 2009).

However, it should be noticed that a consumer segmentation is necessary in this context. Generally speaking, fresh-cut fruits are less likely to get chosen by consumers, maybe because of the higher price or the fact that many customers often believe that processed products may lose their quality and freshness. Although the WTP attached to product processing is on average negative, it appears from the literature that on specific consumption occasions and for certain consumer segments, the demand for ready-to-eat products is growing. As reported by Jaeger and Rose (2008) and by Chinnici et al. (2019), due to the context, consumers prefer to buy fresh-cut fruits for domestic consumption, even if they may have more time for lunch. Moreover, young people are on average more inclined to try innovative products than older consumers (Bernués et al., 2012). The main reasons for consumers to buy ready-to-eat products is due to the easiness of consumption (Chinnici et al., 2019), especially for those products that are difficult to peel such as pineapple or pomegranate (see, for instance, McAdams et al., 2013).

To date only few studies estimated the consumers' WTP for the pomegranate product and its characteristics, regardless of the growing consumers' interest for it; moreover, the most part of the existing research is related to pomegranate fruit juices. In particular, Romano et al. (2016) conducted a survey on a total of 454 consumers in two supermarkets in Rio de Janeiro (Brazil), with the aim of determining consumers' WTP for a vitamin-rich pomegranate juice that preserved the antioxidants content and the aromas typical of the fresh juice. They showed that the WTP decreases when consumers' age and the level of education increase, whereas income and the past consumption are positively correlated. According to Lawless et al. (2013), the intention to purchase pomegranate juice blend is related to the general assessment (taste) of the product and the information reported on the label. The study estimates the WTP for nutraceutical juices (pomegranate juice blend) to maximize consumer acceptance among 100 consumers from the United States; a negative role of familiarity on consumer acceptance (i.e. product linking) emerged. On the contrary, McAdams et al. in 2013 highlighted that familiarity with the product and previous purchase of pomegranate fruit have a positive effect on consumers' WTP. The study, conducted on 203 consumers in Texas, aims to elicit consumers' preferences and their WTP for various pomegranate products through an experimental auction. Similarly, Lawless et al. (2015) estimated the WTP of 228 consumers from the United States through a non-hypothetical auction, showing that the most future-oriented consumers were more likely to purchase innovative products such as nutritional-rich juice blends with

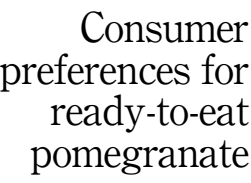

3871 
BFJ

122,12

pomegranate and were willing to pay more for a juice with guaranteed health properties (i.e. authenticity control of minimally processed product); they also demonstrated a positive role of the potential health information on WTP. According to Reis et al. (2016), the juice packaging and the bottle design in particular can override the influence of nutritional or processing information in shaping consumer perception and preference for those who buy a juice (i.e. an orange-pomegranate juice blend) and especially for those who spend little time for grocery shopping and who are therefore more subject to time constraints. Koppel et al. (2014) conducted a study in four different countries (i.e. the United States, Estonia, Thailand and Spain) with the aim of comparing consumers' acceptability for five juices (also a pomegranate juice blend): they showed that, in those countries who produce pomegranate juice, consumer acceptability was greater for the local product (based on the overall liking). Indeed, in some countries where pomegranates are locally grown such as Spain or Turkey, pomegranate juice is considered a traditional product and consumers are familiar with it. In this study we focus our attention on the analysis of consumers' preference for different attributes of pomegranate fruit, such as arils instead of the whole fruit, also estimating the WTP.

\section{Data and method}

Data were gathered in 2019 through an online survey with Italian consumers geographically stratified on the population of each administrative province of Veneto region $(N=626)$ [2]. The sample size of the analysis was determined in order to ensure reliable results: firstly, we set at 300 the minimum number of questionnaires (100 per block), then we extended the data collection in order to maximize the sample size following the indicator of population representativeness of each province, as outlined by the national population census. The research was carried out within a project focussed on analysing consumer preference for pomegranate fruit, thus the product for the experiment was selected based on this. A preliminary survey was carried out in 2018 on a sample of 32 consumers: this aimed at exploring the advantages and disadvantages of buying pomegranate arils instead of the whole fruit through some open-ended questions, while investigating the most preferred product characteristics (both the pomegranate and the arils). In a further step of the research, the final questionnaire was designed based on it: in the first section the consumption habits related to the pomegranate fruit are investigated, namely the purchasing frequency as a screening question to filter only respondents who actually buy pomegranate (otherwise they could not complete the questionnaire). Moreover, the second section contains a choice experiment (CE), while the third section contains 15 Likert scales ( $1=$ total disagree; $7=$ total agree), three for each considered construct of interest such as: people's general preference for ready-to-eat fruits and vegetables $(\mathrm{F} \& \mathrm{~V})$ products $(\mathrm{conv})$; health benefits provided by $\mathrm{F} \& \mathrm{~V}$ (health); F\&V freshness (fresh); preference for shelling the pomegranate (shell); preference for innovative food products (innov). Finally, the last section collected information about socio-demographic characteristics of the sample.

As regards the $\mathrm{CE}$, the choice of the attributes and their levels (Table 1) felt on the most relevant and representative of the pomegranate fruit and arils, following the evidence from our preliminary analysis. More specifically, the product typology attribute refers to the product format, presented as a pack of ready-to-eat arils (100 g) or as the whole fruit (250 g); for the arils, we used the $100 \mathrm{~g}$ package because this is the size that is mainly present in the market for ready-to-eat fruits (e.g. berries), deriving from the shelling of a $250 \mathrm{~g}$ pomegranate fruit. The origin attribute indicates whether the product comes from Italy or is imported from abroad. Regarding the packaging attribute, this refers to the type of packaging which can be eco-friendly (e.g. bioplastic) or conventional.

Theoretically, we should have included the "in bulk" level, because it best describes the purchasing condition of the whole fruit. However, we decide to omit this option because it was not reliable for pomegranate arils, which cannot be sold without packaging. Conversely, selling the whole fruits packaged is feasible, although it is a more unusual and expensive 


\begin{tabular}{|c|c|c|c|}
\hline Attributes & Levels & Code & Consumer \\
\hline Product typology & $\begin{array}{l}\text { (0) pomegranate fruit }(250 \mathrm{~g}) \\
\text { (1) } 100 \mathrm{~g} \text { arils package }\end{array}$ & arils & ready-to-eat \\
\hline Product origin & $\begin{array}{l}\text { (0) other than Italy } \\
\text { (1) Italy }\end{array}$ & orig_ita & pomegranate \\
\hline \multirow[t]{2}{*}{ Packaging } & (0) conventional & & \\
\hline & $\begin{array}{l}\text { (1) eco-friendly } \\
0.39\end{array}$ & pack_eco & 3873 \\
\hline Price $(€ / 250 \mathrm{~g} \text { pomegranate fruit or } € / 100 \mathrm{~g} \text { arils })^{a}$ & $\begin{array}{l}0.79 \\
1.49 \\
2.99\end{array}$ & & $\begin{array}{r}\text { Table } 1 . \\
\text { Description of } \mathrm{CE}\end{array}$ \\
\hline \multicolumn{3}{|c|}{ Note(s): a One package of $100 \mathrm{~g}$ of arils derives from one $250 \mathrm{~g}$ pomegranate fruit } & attributes and levels \\
\hline
\end{tabular}

condition. Moreover, this form of packaging for whole pomegranates actually exists on the Italian market.

Finally, as regards the price attribute, four levels were selected based on the current market prices and estimated prices retrieved both at the supermarket and online (https:// www.miaspesa.it/search/arilli\%20melagrana).

The orthogonal design included 32 possible combinations obtained with the full-factorial design $\left(2^{3} \times 4^{1}\right)$. After that, using IBM SPSS 25.0, we reduced them to 28 combinations through the fractional factorial, keeping the orthogonality of the attributes (Hanley et al., 1998). Finally, all these choice sets were then examined and those that presented pairs of implausible or dominant alternatives were removed, obtaining a total number of 21 choice sets that we divided into three blocks: each respondent had to answer to seven choice sets. In each choice set, respondents were asked to imagine buying a $250 \mathrm{~g}$ package of pomegranate and/or $100 \mathrm{~g}$ of arils; in particular, they were asked to indicate their preference among two multi-attribute alternatives (options A and B) and a "no choice" option (C) (Hensher et al., 2005), where A and B differ in terms of each attribute level and the last alternative guarantees a realistic purchasing scenario (the consumer can choose not to buy the good if its characteristics do not satisfy him/her). Figure 1 displays a screenshot of a choice set. In fact, according to Lancaster (1966), the utility that consumer obtains from a product does not derive from the product itself but from its attributes.

The analytical tool used to estimate the preferences expressed in the $\mathrm{CE}$ is the random utility function (McFadden, 1974) which describes the utility $U$ as the sum of an observable component $V$ and a random error (unobservable) term $\varepsilon$. Among different alternatives, the consumer will choose the alternative $i$ if the utility that he derives from it is larger than the utility from all the other alternatives different from $i$. It follows that the probability that the consumer $n$ chooses the alternative $i$ is described by the following equation:

\begin{tabular}{|c|c|c|c|}
\hline & A & B & $\mathrm{C}$ \\
\hline Product typology & & & \\
\hline Product origin & Italy & other than Italy & \\
\hline Packaging & conventional & eco-friendly & \\
\hline Price ( $\epsilon / 250 \mathrm{~g}$ pomegranate fruit or $\epsilon / 100 \mathrm{~g}$ arils) & 1.49 & 2.99 & \\
\hline Which alternative do you prefer? & $\square$ & $\square$ & $\square$ \\
\hline
\end{tabular}

Figure 1. 


$$
P_{n i}=\operatorname{Prob}\left(V_{n i}+\varepsilon_{n i}>V_{n j}+\varepsilon_{n j}\right) \forall_{j} \neq i
$$

The definition of the choice model to be applied to the CE depends on the assumed existence of different segments of the respondents' population. By considering the heterogeneity of preferences, we assume respondents belong to several latent classes and that their preferences are homogeneous within each segment but different across segments. The latent class model (LCM) estimates specific preferences for each segment: in particular, the utility of consumer $n$ in segment $f$ that chooses the alternative $i$ can be expressed as:

$$
U_{\text {nif }}=X_{n i} \beta_{f}+\varepsilon_{\text {nif }}
$$

where $X_{n i}$ is the vector of product attributes associated with the alternative $i, \beta_{f}$ is the specific vector of preferences for the latent class $f$ and $\varepsilon_{\text {nif }}$ the error term. Hence, the probability of consumer $n$ to choose the alternative $i$ among several alternatives is given by:

$$
\operatorname{Prob}_{n i}=\sum_{f=1}^{F} \frac{\exp \left(\beta_{f} X_{n i}\right)}{\sum_{j} \exp \left(\beta_{f} X_{n j}\right)} \operatorname{Prob}_{n f}
$$

where $F$ is the total number of latent segments, while $\operatorname{Prob}_{n f}$ represents the probability that consumer $n$ belongs to the latent class $f$. Following Boxall and Adamowicz (2002), this latter can be expressed as:

$$
\operatorname{Prob}_{n f}=\frac{\exp \left(\theta_{f} Z_{n}\right)}{\sum_{f=1}^{F} \exp \left(\theta_{f} Z_{n}\right)}
$$

with $\theta_{f}$ representing a specific parameter vector of the latent class $f$ and $Z_{i}$ including the characteristics of consumer $n$ which can be used to explain his segment membership. We estimated $\beta_{f}$ and $\theta_{f}$ via the expectation-maximization (EM) algorithm or latent class logit model (Pacifico and Yoo, 2012) in STATA 16. Hence, we conducted the LCM to identify differences in the $\mathrm{CE}$ across consumer classes; moreover, we estimated a conditional logit model (CL), assuming homogeneous preferences of the respondents.

\section{Results}

As shown in Table 2, the sample is not representative for the Veneto (Italy) population: the investigated sample consists mainly of women $(78 \%)$ and individuals of age less than 45 years (65\%); the majority of the sample have an upper secondary school level of education $(56 \%)$, are employed (80\%) and have a family income of $2,500 €$ per month $(49 \%)$ and three or four family members.

Table 3 shows the descriptive statistics related to the variables measured through the Likert scales. As observable from the mean values, overall we notice that respondents agree with each statement, with the exception of the items for conv (C1, C2 and C3). The responses to the three items considered for each construct were averaged into a composite score (i.e. health, conv, fresh, shell, innov), whose reliability was tested through the Cronbach's $\alpha$ coefficient that shows values always higher than the acceptable threshold of 0.7 . It is worth noting that, generally speaking, a higher value of the scale indicates that people: prefer to buy $F \& V$ with higher health benefits such as products that are rich in polyphenols and antioxidants (health); prefer ready-to-eat products as they are more convenient in terms of time saving (conv); prefer to buy fresh and unprocessed F\&V (e.g. fresh products instead of technologically processed ones) as their genuineness is not compromised in this way (fresh); prefer to purchase the 


\begin{tabular}{|c|c|c|c|c|c|c|}
\hline \multirow[b]{2}{*}{ Variable } & \multirow[b]{2}{*}{ Code } & & \multicolumn{2}{|c|}{$\begin{array}{c}\text { Sample } \\
\text { population }\end{array}$} & \multirow{2}{*}{$\begin{array}{c}\text { Veneto region } \\
\text { population }^{\mathrm{a}} \\
\%\end{array}$} & \multirow{2}{*}{$\begin{array}{l}\text { Consumer } \\
\text { preferences for } \\
\text { ready-to-eat }\end{array}$} \\
\hline & & & N. obs & $\%$ & & \\
\hline \multirow{4}{*}{ Age (years) } & age1 & $18-35$ & 193 & 30.8 & 18.02 & \\
\hline & age2 & $36-45$ & 215 & 34.3 & 14.26 & \\
\hline & age3 & $46-55$ & 152 & 24.3 & 16.81 & \\
\hline & age4 & More than 55 & 66 & 10.5 & 36.16 & 3875 \\
\hline \multirow[t]{2}{*}{ Gender } & sex & Female (1) & 488 & 78.0 & 51.16 & \\
\hline & & Male (0) & 138 & 22.0 & 48.84 & \\
\hline \multirow[t]{3}{*}{ Education level } & edu & Secondary school (1) & 85 & 13.6 & 57.70 & \\
\hline & & $\begin{array}{l}\text { Upper secondary school } \\
\text { (2) }\end{array}$ & 350 & 55.9 & 28.34 & \\
\hline & & University degree (3) & 191 & 30.5 & 13.96 & \\
\hline \multirow[t]{4}{*}{ Occupation } & $\mathrm{occ}$ & Student (1) & 44 & 7.0 & & \\
\hline & & Employed (2) & 500 & 79.9 & & \\
\hline & & Retired (3) & 20 & 3.2 & & \\
\hline & & Unemployed (4) & 62 & 9.9 & & \\
\hline \multirow{3}{*}{$\begin{array}{l}\text { Number of household } \\
\text { members }\end{array}$} & $n \_$fam & $1-2(1)$ & 188 & 23.6 & 60.10 & \\
\hline & & $3-4(2)$ & 381 & 60.8 & 34.60 & \\
\hline & & More than 4 (3) & 57 & 9.2 & 5.20 & \\
\hline \multirow[t]{3}{*}{ Family income (€/month) } & income & Less than 2,500 (1) & 192 & 30.0 & & \\
\hline & & $2,500(2)$ & 306 & 48.9 & & \\
\hline & & More than 2,500 (3) & 128 & 20.4 & & 2 \\
\hline \multicolumn{6}{|c|}{ Note(s): ${ }^{a}$ Data source: Italian National Population Census 2018} & Sample characteristics \\
\hline
\end{tabular}

whole pomegranate instead of ready-to-eat arils as they like shelling the fruit (shell); are used to try innovative products (innov).

Regarding the CE, in both CL and LCM, the reference product is represented by a whole pomegranate fruit $(250 \mathrm{~g}$ ) with a conventional packaging (i.e. using materials that are not recognized as sustainable), the lowest price level and not produced in Italy (i.e. imported); the pseudo $R^{2}$ for the two models is 15 and $62 \%$, respectively.

Firstly, we estimated the CL as the baseline; as shown in Table 4, all the parameters are significant at $1 \%$ level and we appreciate that, generally speaking, respondents prefer to buy the whole fruit $\left(\beta_{\text {arils }}=-0.60\right)$ instead of arils, with an Italian origin $\left(\beta_{\text {orig } \_ \text {ita }}=1.60\right)$, a sustainable packaging $\left(\beta_{\text {pack_eco }}=0.33\right)$ and a lower price $\left(\beta_{\text {price }}=-0.30\right)$. The marginal willingness to pay (mWTP), which was estimated by dividing the coefficient of each attribute of the $\mathrm{CE}$ with the price coefficient, shows that respondents are willing to pay $5.3 € / 250 \mathrm{~g}$ more if the country of production is Italy, $1.1 € / 250 \mathrm{~g}$ more for having a sustainable packaging and $1.9 € / 250 \mathrm{~g}$ less for having the arils instead of the entire fruit (Table 5). The value of the WTP related to the Italian origin could seem very high. In this context, it is worth to notice that, being the WTP a monetary estimate of the consumer surplus derived by consuming a specific product, it could be possible that this value does not reflect the amount actually paid by consumers. Indeed, in many cases, these estimates exceed the real prices paid for a certain product (Poelmans and Rousseau, 2016). Besides, we selected a four-segment LCM as the more parsimonious description of the latent class structure through the Consistent Akaike Information Criterion (CAIC) index: in particular, the fourth represents the reference class and, based on it, we described the other classes and labelled them by comparing the segment membership parameters.

The first class represents the "eco-friendly" consumers ( $26 \%$ of the respondents), namely those who prefer buying the whole fruit $\left(\beta_{\text {arils }}=-1.63\right)$ packaged with a sustainable material 


\section{$\mathrm{BFJ}$} 122,12
Scale items

Health (health) (Cronbach's $a=0.768)$

H1 - When purchasing F\&V, I choose products with higher health benefits

$\mathrm{H} 2$ - I usually eat F\&V rich in polyphenols and antioxidants

H3 - When purchasing F\&V, I prefer to consume products with a potential positive impact on my health status

\section{6}

Table 3.

Likert scales for measuring consumer preference
Convenience $(\mathrm{conv})$ (Cronbach's $a=0.658)$

$\mathrm{C} 1$ - At the moment of purchase, I search for convenient (ready-to-eat) F\&V $\quad 3.88 \quad 1.67$

C2 - I think that ready-to-eat F\&V are easy to use $\quad 3.16 \quad 1.93$

C3 - For me consuming fresh-cut F\&V is easier $\quad 3.72 \quad 1.90$

Freshness (fresh) (Cronbach's $a=0.794)$

F1 - I prefer to buy fresh F\&V (e.g. the whole fruit) because I think that technological processes $\quad 6.07 \quad 1.25$

can compromise the organoleptic characteristics of the product

F2 - When it comes to F\&V, I think that the processing can alter the freshness of the products $\quad 5.55 \quad 1.42$

F3 - I think that the genuineness of the product can be compromised by the technological $\quad 5.41 \quad 1.55$

process, especially for $\mathrm{F} \& \mathrm{~V}$

Shelling (shell) (Cronbach's $a=0.823$ )

S1 - I prefer to purchase pomegranate instead of ready-to-eat arils because I like to shell the $\quad 5.08 \quad 1.91$ pomegranate

S2 - I think that by shelling the pomegranate I can live a more complete consumption $\quad 5.08 \quad 1.89$ experience than with ready-to-eat arils

S3 - Between the whole pomegranate and the arils, I prefer buying the whole fruit as shelling is $\quad 5.18 \quad 1.89$ not really boring to me

Innovation (innov) (Cronbach's $a=0.827$ )

N1 - Generally speaking, I love to try innovative food $\quad 4.82 \quad 1.51$

N2 - Generally speaking, I'm curious to taste food products that I usually do not consume $\quad 4.99 \quad 1.56$

N3 - In my opinion, it is always worth trying innovative products $\quad 5.21 \quad 1.41$

Note(s): The scale measure is $1=$ totally disagree; $7=$ totally agree. F\&V stands for fruits and vegetables

as a bioplastic or another recycled material $\left(\beta_{\text {pack_eco }}=1.42\right)$ and produced in Italy $\left(\beta_{\text {orig_ita }}=1.12\right)$; here the price attribute is not significant.

Consumers in the second class are named "time-saving lovers" ( $21 \%$ of the respondents) as they are likely to buy ready-to-eat arils instead of the whole fruit $\left(\beta_{\text {arils }}=1.92\right)$. Moreover, being this product a novelty in the Italian market, customers in this segment are prone to try innovative products. For having $100 \mathrm{~g}$ of ready-to-eat arils instead of a $250 \mathrm{~g}$ pomegranate, they are willing to pay $4 €$ more. Moreover, consumers in this segment are likely to choose a product produced in Italy $\left(\beta_{\text {orig_ita }}=1.68\right)$, sustainably packaged $\left(\beta_{\text {pack_eco }}=0.71\right)$ and with a low price $\left(\beta_{\text {price }}=-0.48\right)$.

The third class gathers the so-called "nationalists", namely consumers that prefer the Italian origin of the product $\left(\beta_{\text {orig ita }}=4.31\right)$ instead of a foreign origin and who are willing to pay $7.5 € / 250 \mathrm{~g}$ more for it. They also prefer buying the whole fruit instead of arils $\left(\beta_{\text {arils }}=-1.67\right)$ and paying a lower price for it $\left(\beta_{\text {price }}=-0.58\right)$; in this segment the attribute packaging is not significant.

Finally, the fourth class collects the "price sensitive" consumers that are those who are characterized by being highly interested in paying less for the product $\left(\beta_{\text {price }}=-12.99\right)$, in addition to prefer an Italian $\left(\beta_{\text {orig_ita }}=37.09\right)$ and whole fruit $\left(\beta_{\text {arils }}=-29.61\right)$ that is also conventionally packaged $\left(\beta_{\text {pack_eco }}=-26.86\right)$. For having an Italian product, a sustainable packaging and arils instead of the whole fruit they are willing to pay $2.9 € / 250 \mathrm{~g}$ more and $2.1 €$ and $2.3 € / 250 \mathrm{~g}$ less, respectively.

Looking at the membership parameters, we notice that, compared to the fourth class, consumers in the first class prefer buying ready-to-eat products as they are more convenient 


\begin{tabular}{|c|c|c|c|c|c|c|}
\hline & $\begin{array}{l}\text { Conditional } \\
\text { logit }\end{array}$ & $\begin{array}{c}\text { Class } 1 \\
\text { Eco- } \\
\text { friendly }\end{array}$ & $\begin{array}{l}\text { Latent c } \\
\text { Class } 2 \\
\text { Time-saving } \\
\text { lovers }\end{array}$ & $\begin{array}{l}\text { model } \\
\text { Class } 3 \\
\text { Nationalists }\end{array}$ & $\begin{array}{c}\text { Class } 4 \\
\text { Price } \\
\text { sensitive }\end{array}$ & $\begin{array}{l}\text { ponsumer } \\
\text { preferences for } \\
\text { ready-to-eat } \\
\text { pomegranate }\end{array}$ \\
\hline \multicolumn{7}{|l|}{ CE attributes } \\
\hline Price & $\begin{array}{l}-0.300^{* * * *} \\
(0.025)\end{array}$ & $\begin{array}{r}-0.093 \\
(0.066)\end{array}$ & $\begin{array}{l}-0.476^{* * * *} \\
(0.069)\end{array}$ & $\begin{array}{l}-0.577^{* * * *} \\
(0.129)\end{array}$ & $\begin{array}{l}-12.988^{* * * *} \\
(3.978)\end{array}$ & 3877 \\
\hline orig_ita & $\begin{array}{l}1.597 * * * \\
(0.051)\end{array}$ & $\begin{array}{l}1.124^{* * *} \\
(0.203)\end{array}$ & $\begin{array}{l}1.684^{* * * *} \\
(0.134)\end{array}$ & $\begin{array}{l}4.306^{* * * *} \\
(0.381)\end{array}$ & $\begin{array}{l}37.087^{* * * *} \\
(11.882)\end{array}$ & \\
\hline pack_eco & $\begin{array}{l}0.331^{* * * *} \\
(0.049)\end{array}$ & $\begin{array}{l}1.422^{* * * *} \\
(0.148)\end{array}$ & $\begin{array}{l}0.705^{* * *} \\
(0.127)\end{array}$ & $\begin{array}{c}-0.087 \\
(0.221)\end{array}$ & $\begin{array}{c}-26.855^{* * * *} \\
(8.758)\end{array}$ & \\
\hline p_type & $\begin{array}{c}-0.590 * * * \\
(0.045)\end{array}$ & $\begin{array}{l}-1.625^{* * * *} \\
(0.158)\end{array}$ & $\begin{array}{l}1.922^{* * * *} \\
(0.155)\end{array}$ & $\begin{array}{l}-1.669 * * * \\
(0.255)\end{array}$ & $\begin{array}{c}-29.609 * * * \\
(8.790)\end{array}$ & \\
\hline \multicolumn{7}{|c|}{ Membership parameters } \\
\hline \multicolumn{2}{|l|}{ Health } & $\begin{array}{r}-0.181 \\
(0.159)\end{array}$ & $\begin{array}{c}-0.339 * \\
(0.174)\end{array}$ & $\begin{array}{r}-0.106 \\
(0.145)\end{array}$ & & \\
\hline Conv & & $\begin{array}{l}0.199^{*} \\
(0.108)\end{array}$ & $\begin{array}{l}0.676^{* * * *} \\
(0.129)\end{array}$ & $\begin{array}{l}0.292^{* * * *} \\
(0.100)\end{array}$ & & \\
\hline Fresh & & $\begin{array}{c}-0.367 * * \\
(0.174)\end{array}$ & $\begin{array}{c}-0.566^{* * * *} \\
(0.176)\end{array}$ & $\begin{array}{c}-0.282^{*} \\
(0.160)\end{array}$ & & \\
\hline Shell & & $\begin{array}{c}0.093 \\
(0.119)\end{array}$ & $\begin{array}{l}-0.418^{* * * *} \\
(0.113)\end{array}$ & $\begin{array}{r}-0.058 \\
(0.098)\end{array}$ & & \\
\hline Innov & & $\begin{array}{c}0.058 \\
(0.119)\end{array}$ & $\begin{array}{c}0.024 \\
(0.145)\end{array}$ & $\begin{array}{r}-0.078 \\
(0.106)\end{array}$ & & \\
\hline Sex & & $\begin{array}{r}-0.092 \\
(0.341)\end{array}$ & $\begin{array}{r}-0.253 \\
(0.389)\end{array}$ & $\begin{array}{c}0.122 \\
(0.327)\end{array}$ & & \\
\hline Income & & $\begin{array}{c}0.020 \\
(0.211)\end{array}$ & $\begin{array}{c}0.006 \\
(0.235)\end{array}$ & $\begin{array}{r}-0.071 \\
(0.192)\end{array}$ & & \\
\hline Edu & & $\begin{array}{r}-0.345 \\
(0.232)\end{array}$ & $\begin{array}{r}-0.108 \\
(0.272)\end{array}$ & $\begin{array}{r}-0.272 \\
(0.211)\end{array}$ & & \\
\hline n_fam & & $\begin{array}{c}0.118 \\
(0.127)\end{array}$ & $\begin{array}{c}0.274^{*} \\
(0.146)\end{array}$ & $\begin{array}{c}0.131 \\
(0.115)\end{array}$ & & \\
\hline age1 & & $\begin{array}{c}0.278 \\
(0.423)\end{array}$ & $\begin{array}{l}1.043^{*} \\
(0.548)\end{array}$ & $\begin{array}{c}0.104 \\
(0.423)\end{array}$ & & \\
\hline age2 & & $\begin{array}{r}-0.772^{*} \\
(0.456)\end{array}$ & $\begin{array}{c}0.213 \\
(0.560)\end{array}$ & $\begin{array}{r}-0.066 \\
(0.403)\end{array}$ & & \\
\hline age3 & & $\begin{array}{r}-0.801^{*} \\
(0.467)\end{array}$ & $\begin{array}{c}0.176 \\
(0.587)\end{array}$ & $\begin{array}{r}-0.413 \\
(0.425)\end{array}$ & & \\
\hline age4 & & $\begin{array}{c}0.092 \\
(0.561)\end{array}$ & $\begin{array}{r}-0.208 \\
(0.817)\end{array}$ & $\begin{array}{c}0.244 \\
(0.542)\end{array}$ & & \\
\hline Cons & & $\begin{array}{l}2.790^{*} \\
(1.488)\end{array}$ & $\begin{array}{l}3.702^{* *} \\
(1.613)\end{array}$ & $\begin{array}{l}2.920^{* * *} \\
(1.395)\end{array}$ & & \\
\hline Class probability & & 0.264 & 0.212 & 0.339 & 0.186 & \\
\hline N. obs & 13,146 & & & & & \\
\hline Log-likelihood & $-4,102.2698$ & & $-3,1$ & 9908 & & \\
\hline $\begin{array}{l}\text { McFadden's pseudo } \\
R^{2}\end{array}$ & 0.148 & & & & & $\begin{array}{r}\text { Table } 4 . \\
\text { Estimation results: }\end{array}$ \\
\hline $\begin{array}{l}\text { Note(s): * Significar } \\
\text { in parentheses }\end{array}$ & $10 \%$ level; $* *$ & nificance at & evel; $* * *$ Signifi & ce at $1 \%$ level. & tandard errors & $\begin{array}{l}\text { conditional logit and } \\
\text { latent class model }\end{array}$ \\
\hline
\end{tabular}

in terms of time saving $\left(\beta_{\text {conv }}=0.20\right.$, significant at $10 \%$ level), whereas the more they think that fresh products guarantee their genuineness better than those that are technologically processed and the less they belong to this first class $\left(\beta_{\text {fresh }}=-0.37\right.$, significant at $5 \%$ level). Furthermore, people aged $36-55$ years are less likely to belong to this class $\left(\beta_{\text {age } 2}=-0.77\right.$ and $\beta_{\text {age3 }}=-0.80$, both significant at $10 \%$ level), compared to class 4 . As regards the second 
BFJ

122,12

\section{8}

Table 5.

Marginal willingness to pay $(€ / 250 \mathrm{~g}$ pomegranate or $€ / 100 \mathrm{~g}$ arils) for $\mathrm{CE}$ attributes class, we can affirm that the time-saving lovers are more likely to be 18-35 years old $\left(\beta_{\text {age } 1}=1.04\right.$, significant at $10 \%$ level $)$ than the price sensitive consumers, and they have a large family $\left(\beta_{\mathrm{n} \text { fam }}=0.27\right.$, significant at $1 \%$ level). Compared to the other classes, the individuals of this segment are more likely to buy ready-to-eat products $\left(\beta_{\text {conv }}=0.68\right.$, significant at $1 \%$ level) and less likely to think that fresh products are more genuine than processed ones $\left(\beta_{\text {fresh }}=-0.57\right.$, significant at $1 \%$ level) and to prefer shelling the pomegranate fruit $\left(\beta_{\text {shell }}=-0.42\right.$ with significance level at $\left.1 \%\right)$ as expected. What is more, when buying $F \& V$ generally they are not interested in choosing products with recognized health benefits (e.g. with high content of polyphenols and antioxidants) $\left(\beta_{\text {health }}=-0.34\right.$, significant at $10 \%$ level). Compared to the fourth class, the nationalists prefer buying readyto-eat products $\left(\beta_{\text {conv }}=0.29\right.$, significant at $1 \%$ level), whereas they do not prefer buying fresh $\mathrm{F} \& \mathrm{~V}$ instead of processed products $\left(\beta_{\text {fresh }}=-0.28\right.$, significant at $10 \%$ level). To sum up, the higher is the preference for ready-to-eat products and the more likely individuals belong to class 2 , followed by class 3 and 1, respectively. Conversely, the lower is the preference for unprocessed (fresh) products and the more likely subjects are members of the second segment, followed by class 1 and 3 , respectively.

\section{Discussion}

This study aims at investigating the effect of the ready-to-eat attribute on consumers' preferences and WTP for the pomegranate fruit, in addition to other attributes as the product origin, the price and the packaging typology. Interestingly, our results suggest that the segment that is most prone to buy ready-to-eat arils is characterized by young consumers with a preference for convenience goods. These results agree with what stated by Larson et al. (2006), which found a greater predisposition of young people to purchase ready-to-eat product as they usually spend less time and effort in preparing meals; moreover, young people are generally more inclined to try innovative product than older consumers (Bernués et al., 2012). Accordingly, as stressed by the literature, in recent decades more than $60 \%$ of the expenditure in F\&V has been represented by pre-packaged products (Pollard et al., 2002). To this purpose, Chinnici et al. (2019) found that the $55 \%$ of a sample of 250 Italian consumers regularly eat fresh-cut vegetables. This increase in the ready-to-eat demand is attributable to an overall change in the lifestyle (Lichtenstein et al., 2010; Thienhirun and Chung, 2018) as consumers are currently less inclined to spend time preparing food and willing to spend more money for convenience food guaranteeing their time saving (Gatley et al., 2014; Tallant et al., 2018). Moreover, we found that the "time-saving lovers", which are mainly young people, are less inclined to look for more healthy products when purchasing $\mathrm{F} \& \mathrm{~V}$; the inverse relation between age and health attention is in line with Roininen et al. (1999) and Ragaert et al. (2004). The results show that respondents in the first three segments generally think that the products' freshness is guaranteed for processed $\mathrm{F} \& \mathrm{~V}$, whereas the concern of a possible loss in freshness due to the shelling of the pomegranate fruit regards only the fourth class ("price sensitive") that, accordingly, shows a negative WTP for ready-to-eat arils. The literature

\begin{tabular}{lccccc}
\hline & \multicolumn{4}{c}{ Latent class model } \\
& Conditional logit & $\begin{array}{c}\text { Class 1 } \\
\text { Eco-friendly }\end{array}$ & $\begin{array}{c}\text { Class 2 } \\
\text { Time-saving lovers }\end{array}$ & $\begin{array}{c}\text { Class 3 } \\
\text { Nationalists }\end{array}$ & $\begin{array}{c}\text { Class 4 } \\
\text { Price sensitive }\end{array}$ \\
\hline orig_ita & 5.3 & - & 3.5 & 7.5 & 2.9 \\
pack_eco & 1.1 & - & 1.5 & - & -2.1 \\
Arils & -2.0 & - & 4.0 & -2.9 & -2.3 \\
Note(s): Marginal WTP are shown only for significant variables from CL and LCM & \\
\hline
\end{tabular}


reports that consumers have a divergent view with respect to the linkage between the freshness loss in convenience food and the typology of processing and/or production methods. To this purpose, by conducting a survey on 225 potential consumers of processed food, Cardello et al. (2007) found that treatments that are less invasive on the product (e.g. high-pressure processing) gain a higher consumer utility compared to others (e.g. genetic modification, irradiation, etc.), as they allow to maintain the product genuineness.

With regard to the country of origin, findings show that national pomegranates are more appreciated by all the segments, although the "nationalists" report the highest WTP for the Italian origin. This is consistent with what reported by Moser et al. (2012), who found a great importance for the local origin as well as the national one on apples. The origin, in fact, has a symbolic and affective value and can be considered as a quality signal (Verlegh and Steenkamp, 1999), so much so that consumers often use it as a discriminating attribute for their purchases (Erdem et al., 2006). Nevertheless, the literature (see, for instance, Giampietri et al., 2016) suggests that the origin can play a subordinate role when consumers are directly in contact with the producers. When it comes to the packaging, we found that both the "ecofriendly" and the "time-saving lovers" prefer a more ecological (e.g. biodegradable) packaging to a conventional one, as opposite to the "price sensitive" segment. Particularly, the "eco-friendly" class is mainly composed by medium-age consumers (36-55-year-old people), in line with Laroche et al. (2001). Finally, as expected, we found that price plays a fundamental role at the time of purchase: in particular, for each class except for the first, the price has a negative and significant effect, which indicates that the propensity to purchase decreases when the price increases. These results agree with what reported by Ranasingha et al. (2019), who, by conducting a CE on pomegranates and other fruits, found that price is always inversely proportional to the purchasing choice. Recently, Darko et al. (2013) and Christensen et al. (2019) reported that price can be considered a barrier to buying F\&V, especially for low-income categories. This is presumably due to the fact that F\&V are notoriously expensive, especially for products out of season, such as the pomegranate, which is not always available on the shelf over the year.

\section{Conclusion}

Nowadays, the society is increasingly dynamic and lives many far-reaching changes, ranging from the increase in the world population to the impacts of climate change and an increased consumer focus on healthy diets. Modern consumers are less and less inclined to spend time preparing food and the recent trends consider a significant growth in fresh $\mathrm{F} \& \mathrm{~V}$ consumption especially out-of-home, so the demand for ready-to-eat products is globally spreading. This presents a challenge for the producers and the food industry that must consider these patterns and precisely target the consumers in terms of what, how and where they consume, in order to develop their future marketing strategies. According to the literature, the results show that, among others, the convenience attribute is a relevant factor to consider when consumers choose to buy food. Regarding the pomegranate fruit, albeit the modern appeal among consumers is due to its recognized health benefits, it is possible to gather that the healthiness can be even subordinated to its ease of use, as this fruit notoriously must be shelled. Based on our results, arils are preferred by consumers that do not motivate their choice of F\&V on health benefit. This may imply that, by increasing the availability of readyto-eat arils on the market, it could be possible to support the consumption of pomegranate also by those consumers that usually do not purchase F\&V for its healthiness. As we note by the findings, the ready-to-eat attribute is mostly preferred by young people that, as highlighted in the literature, are also the most prepared to try new products such as packaged arils. This evidence provides some interesting marketing inputs for producers: indeed, they may be inspired to implement marketing strategies that are specific for young subjects, for

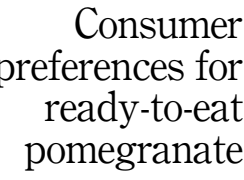

3879 
$\mathrm{BFJ}$

122,12

example, creating an appealing packaging design or promotional campaigns more appropriate to this population segment, or presenting this product as a snack proposal. Moreover, as the recent literature on fruit consumption has widely pointed to the importance of product availability as a relevant factor to promote an increased intake also among youngers (see, for instance, Bonanno et al., 2017; van den Bogerd et al., 2019), producers should consider to place this ready-to-eat product especially in schools or university environments such as canteens, libraries, cafeterias or amusement arcades, to make it more accessible to potential consumers. Conversely, findings show that ready-to-eat arils are not preferred by the other three classes of consumers: taking into account the heterogeneity in their preferences and working on the marketing mix, producers may develop a product line, where each product represents a specific bundle of characteristics and one of these is particularly developed, namely the one most preferred by a specific class (for instance, the national origin for class 3 , the lower price for class 4 , the eco-friendly packaging for class 1 ). This process should be driven by a preliminary research activity involving targeted customer surveys, market analyses and also cost analysis for producers. Nevertheless, it should be considered that the ongoing trend is increasingly moving towards ready-to-eat products. This means that, with appropriate marketing strategies and a targeted promotion that highlight the attributes appreciated by consumers, the ready-to-eat arils could be purchased also by consumers who do not belong to class 2 , but that shows a positive attitude towards the convenience attribute (i.e. class 1 and 3 ).

Furthermore, actually packaged arils are not largely present on the Italian market but, following our results, we can assume that the presence of the ready-to-eat format on the shelf may raise the accessibility to the pomegranate fruit and consequently its consumer demand. Indeed, due to its seasonality, pomegranate suffers by nature from a lack of supply during certain periods of the year. In this regard, new cultivars and new conservation techniques are currently being tested worldwide to increase the product shelf-life. It is worth noting that a barrier to the consumption of the ready-to-eat product may be linked to the general perception that food processing can somehow alter the freshness of the fruit. However, in the case of pomegranate it should be noted that a proper shelling allows to maintain the product's genuineness; moreover, the high polyphenol content of the fruit ensures a longer and more natural shelf-life of the product. Moreover, findings related to the preference for the Italian origin of the product light up to new opportunities to producers in Veneto region to increase the local production of pomegranate, perhaps implementing technologies for product transformation. In particular, it could be convenient for farms or cooperatives that already produce pomegranate juice to buy an equipment that delicately shells the pomegranate. Water pomegranate shellers already exist on the market, which allow to better preserve the quality characteristics of the arils. Moreover, the existing literature highlights that juices obtained by extracting separated arils instead of pressing the whole fruit obtain higher scores of liking by the consumers. However, each company should assess in advance whether the consumer's WTP for the ready-to-eat arils covers the investment costs required. It follows that further research on improved and more sustainable production techniques should be implemented to ensure the local supply. The research presents some limitations such as the non-representativeness of the sample and the hypothetical nature of the experiment. Further research will investigate consumers' stated preferences with a sensory panel, a consumer test and a representative region-wide survey, also testing different pomegranate cultivars.

\section{Notes}

1. The product code HS-08109075 includes, among others, pomegranates and other fruits including cherimoya, barbary figs and medlars (more information are available at: https://www.cbi.eu/marketinformation/fresh-fruit-vegetables/pomegranates/europe/\#). 
2. Consumers from all the seven provinces of Veneto region were surveyed: in particular, 142 selfadministered questionnaires were completed in Venezia (23\% of total questionnaires), 134 in Treviso $(21 \%), 107$ in Padova (17\%), 101 in Verona (16\%), 87 in Vicenza (14\%), 33 in Rovigo (5\%) and 23 in Belluno (4\%). It is worth noting that in some cases the percentages are slightly overestimated or underestimated and this depends on the fact that incomplete questionnaires were eliminated. However, we guaranteed the full representativeness of the two least populated provinces (Belluno and Rovigo).

Consumer preferences for ready-to-eat pomegranate

\section{References}

Al-Maiman, S.A. and Ahmad, D. (2002), "Changes in physical and chemical properties during pomegranate (Punica granatum L.) fruit maturation”, Food Chemistry, Vol. 76 No. 4, pp. 437-441.

Alcaraz-Mármol, F., Calín-Sánchez, Á., Nuncio-Jáuregui, N., Carbonell-Barrachina, Á.A., Hernández, F. and Martínez, J.J. (2015), "Classification of pomegranate cultivars according to their seed hardness and wood perception”, Journal of Texture Studies, Vol. 46 No. 6, pp. 467-474.

Ana, I.D.A., Schoolmeester, D., Dekker, M. and Jongen, W.M. (2007), "To cook or not to cook: a meansend study of motives for choice of meal solutions", Food Quality and Preference, Vol. 18 No. 1, pp. $77-88$.

Bernués, A., Ripoll, G. and Panea, B. (2012), "Consumer segmentation based on convenience orientation and attitudes towards quality attributes of lamb meat", Food Quality and Preference, Vol. 26 No. 2, pp. 211-220.

Bonanno, A., Bimbo, F., Castellari, E. and Sckokai, P. (2017), "Five-a-day, fruit and vegetables portions, and the food environment: the Italian case", Applied Economic Perspectives and Policy, Vol. 39 No. 4, pp. 682-709.

Boxall, P.C. and Adamowicz, W.L. (2002), "Understanding heterogeneous preferences in random utility models: a latent class approach”, Environmental and Resource Economics, Vol. 23 No. 4, pp. 421-446.

Caleb, O.J., Opara, U.L. and Witthuhn, C.R. (2012), "Modified atmosphere packaging of pomegranate fruit and arils: a review", Food and Bioprocess Technology, Vol. 5 No. 1, pp. 15-30.

Calín-Sánchez, Á., Martínez, J.J., Vázquez-Araújo, L., Burló, F., Melgarejo, P. and Carbonell-Barrachina, Á.A. (2011), "Volatile composition and sensory quality of Spanish pomegranates (Punica granatum L.)", Journal of the Science of Food and Agriculture, Vol. 91 No. 3, pp. 586-592.

Cardello, A.V., Schutz, H.G. and Lesher, L.L. (2007), "Consumer perceptions of foods processed by innovative and emerging technologies: a conjoint analytic study", Innovative Food Science and Emerging Technologies, Vol. 8 No. 1, pp. 73-83.

Chinnici, G., Di Grusa, A. and D’Amico, M. (2019), "The consumption of fresh-cut vegetables: features and purchasing behaviour", Quality-Access to Success, Vol. 20, pp. 178-185.

Christensen, T., Denver, S. and Bøye Olsen, S. (2019), "Consumer preferences for organic food and for the shares of meat and vegetables in an everyday meal", Journal of International Food and Agribusiness Marketing, Vol. 1 No. 13, pp. 1-13.

Continella, A., Restuccia, C., Brighina, S., Pannitteri, C. and La Malfa, S. (2018), "Microbiological and qualitative aspects of minimally processed pomegranate seeds", Acta Horticulturae, Vol. 1209, pp. 379-384.

Dandachi, F., Hamadeh, B., Youssef, H., Chahine, H. and Chalak, L. (2017), "Diversity assessment of the Lebanese germplasm of pomegranate (Punica granatum $L$.) by morphological and chemical traits", Annals of Agricultural Sciences, Vol. 62 No. 1, pp. 89-98.

Darko, J., Eggett, D.L. and Richards, R. (2013) "Shopping behaviors of low-income families during a 1month period of time", Journal of Nutrition Education and Behavior, Vol. 45 No. 1, pp. 20-29.

Erdem, T., Swait, J. and Valenzuela, A. (2006), "Brands as signals: a cross-country validation study", Journal of Marketing, Vol. 70 No. 1, pp. 34-49. 
$\mathrm{BFJ}$

122,12

\section{2}

Ergun, M. and Ergun, N. (2009), "Maintaining quality of minimally processed pomegranate arils by honey treatments", British Food Journal, Vol. 111 No. 4, pp. 396-406.

Faria, A. and Calhau, C. (2011), "The bioactivity of pomegranate: impact on health and disease the bioactivity of pomegranate: impact on health and disease", Critical Reviews in Food Science and Nutrition, Vol. 51 No. 7, pp. 626-634.

Gatley, A., Caraher, M. and Lang, T. (2014), "A qualitative, cross cultural examination of attitudes and behaviour in relation to cooking habits in France and Britain", Appetite, Vol. 75, pp. $71-81$.

Geveke, D.J., Sites, J.E., Guo, M., Wang, L., Fan, X. and Jin, T.Z. (2013), "Evaluation of microbial stability, bioactive compounds, physicochemical properties, and consumer acceptance of pomegranate juice processed in a commercial scale pulsed electric field system", Food and Bioprocess Technology, Vol. 7 No. 7, pp. 2112-2120.

Giampietri, E., Koemle, D., Yu, X. and Finco, A. (2016), “Consumers' sense of farmers' markets: tasting sustainability or just purchasing food?", Sustainability, Vol. 8 No. 11, p. 1157.

Gil, M.I., Tomas-Barberan, F.A., Hess-Pierce, B., Holcroft, D.M. and Kader, A.A. (2000), "Antioxidant activity of pomegranate juice and its relationship with phenolic composition and processing", Journal of Agricultural and Food Chemistry, Vol. 48 No. 10, pp. 4581-4589.

Guo, S., Deng, Q., Xiao, J., Xie, B. and Sun, Z. (2007), "Evaluation of antioxidant activity and preventing DNA damage effect of pomegranate extracts by chemiluminescence method", Journal of Agricultural and Food Chemistry, Vol. 55 No. 8, pp. 3134-3140.

Hanley, N., MacMillan, D., Wright, R.E., Bullock, C., Simpson, I., Parsisson, D. and Crabtree, B. (1998), "Contingent valuation versus choice experiments: estimating the benefits of environmentally sensitive areas in Scotland", Journal of Agricultural Economics, Vol. 49 No. 1, pp. 1-15.

Hensher, D.A., Rose, J.M. and Greene, W.H. (2005), Applied Choice Analysis: A Primer, Cambridge University Press, Cambridge, UK.

Holland, D. and Bar-Ya'akov, I. (2008), "The pomegranate: new interest in an ancient fruit", Chronica Horticulturae, Vol. 48 No. 3, pp. 12-15.

Howell, A.B. and D'Souza, D.H. (2013), "The Pomegranate: effects on bacteria and viruses that influence human health", Evidence-Based Complementary and Alternative Medicine, Vol. 2013, pp. 1-11.

Jaeger, S.R. and Rose, J.M. (2008), "Stated choice experimentation, contextual influences and food choice: a case study", Food Quality and Preference, Vol. 19 No. 6, pp. 539-564.

Karimi, M., Sadeghi, R. and Kokini, J. (2017), "Pomegranate as a promising opportunity in medicine and nanotechnology", Trends in Food Science and Technology, Vol. 69, pp. 59-73.

Koppel, K., Chambers, E., Vázquez-Araújo, L., Timberg, L., Carbonell-Barrachina, Á.A. and Suwonsichon, S. (2014), "Cross-country comparison of pomegranate juice acceptance in Estonia, Spain, Thailand and United States", Food Quality and Preference, Vol. 31 No. 1, pp. 116-123.

Kulkarni, A.P., Mahal, H.S., Kapoor, S. and Aradhya, S.M. (2007), "In vitro studies on the binding antioxidant and cytotoxic action of punicalagin", Journal of Agricultural and Food Chemistry, Vol. 55 No. 4, pp. 1491-1500.

Lähteenmäki, L., Lampila, P., Grunert, K., Boztug, Y., Ueland, Ø., Åström, A. and Martinsdóttir, E. (2010), "Impact of health-related claims on the perception of other product attributes", Food Policy, Vol. 35 No. 3, pp. 230-239.

Lancaster, K.J. (1966), “A new approach to consumer theory”, Current, Vol. 74 No. 2, pp. 132-157.

Laroche, M., Bergeron, J. and Barbaro-Forleo, G. (2001), "Targeting consumers who are willing to pay more for environmentally friendly products", Journal of Consumer Marketing, Vol. 18 No. 6, pp. 503-520. 
Larson, N.I., Perry, C.L., Story, M. and Neumark-Sztainer, D. (2006), "Food preparation by young adults is associated with better diet quality", Journal of the American Dietetic Association, Vol. 106 No. 12, pp. 2001-2007.

Lawless, L.J.R., Drichoutis, A.C., Nayga, R.M., Threlfall, R.T. and Meullenet, J.F. (2015), “Identifying product attributes and consumer attitudes that impact willingness to pay for a nutraceuticalrich juice product”, Journal of Sensory Studies, Vol. 30 No. 2, pp. 156-168.

Lawless, L.J.R., Threlfall, R.T., Meullenet, J.F. and Howard, L.R. (2013), "Applying a mixture design for consumer optimization of black cherry, concord grape and pomegranate juice blends", Journal of Sensory Studies, Vol. 28 No. 2, pp. 102-112.

Lichtenstein, A.H. and Ludwig, D.S. (2010), "Bring back home economics education", JAMA, Vol. 303 No. 18 , pp. 1857-1858.

Martínez, J.J., Hernández, F., Abdelmajid, H., Legua, P., Martínez, R., El Amine, A. and Melgarejo, P. (2012), "Physico-chemical characterization of six pomegranate cultivars from Morocco: processing and fresh market aptitudes”, Scientia Horticulturae, Vol. 140, pp. 100-106.

Mayuoni-Kirshenbaum, L., Bar-Ya'akov, I., Hatib, K., Holland, D. and Porat, R. (2013), "Genetic diversity and sensory preference in pomegranate fruits", Fruits, Vol. 68 No. 6, pp. 517-524.

McAdams, C.P., Palma, M.A., Hall, C.R. and Ishdorj, A. (2013), "A nonhypothetical ranking and auction mechanism for novel products", Journal of Agricultural and Applied Economics, Vol. 45, pp. 35-52.

McFadden, D. (1974), "Conditional logit analysis of qualitative choice behavior”, in Zarembka, P. (Ed.), Frontiers in Econometrics, Academic Press, New York, USA, pp. 105-142.

Mena, P., García-Viguera, C., Navarro-Rico, J., Moreno, D.A., Bartual, J., Saura, D. and Martí, N. (2011), "Phytochemical characterisation for industrial use of pomegranate (Punica granatum L.) cultivars grown in Spain", Journal of the Science of Food and Agriculture, Vol. 91 No. 10, pp. 893-1906.

Moser, R. and Raffaelli, R. (2012), "Consumer preferences for sustainable production methods in apple purchasing behaviour: a non-hypothetical choice experiment", International Journal of Consumer Studies, Vol. 36 No. 2, pp. 141-148.

Pacifico, D. and Yoo, H.I. (2012), A Stata Module for Estimating Latent Class Conditional Logit Models via the Expectation-Maximization Algorithm, Australian School of Business Research Paper, University of New South Wales, Sydney.

Poelmans, E. and Rousseau, S. (2016), "How do chocolate lovers balance taste and ethical considerations?", British Food Journal, Vol. 118 No. 2, pp. 343-361.

Pollard, J., Kirk, S.L. and Cade, J.E. (2002), "Factors affecting food choice in relation to fruit and vegetable intake: a review”, Nutrition Research Reviews, Vol. 15 No. 2, pp. 373-387.

Pula, K., Parks, C.D. and Ross, C.F. (2014), "Regulatory focus and food choice motives. Prevention orientation associated with mood, convenience, and familiarity", Appetite, Vol. 78, pp. 15-22.

Ragaert, P., Verbeke, W., Devlieghere, F. and Debevere, J. (2004), “Consumer perception and choice of minimally processed vegetables and packaged fruits”, Food Quality and Preference, Vol. 15 No. 3, pp. 259-270.

Ranasingha, R.G.S.M., Edirisinghe, J.C. and Ratnayake, R.H.M.K. (2019), "Willingness to pay for fruit attributes: a conjoint analysis", Journal of Agricultural Sciences-Sri Lanka, Vol. 14 No. 2, pp. 102-110.

Reis, F., Machín, L., Rosenthal, A., Deliza, R. and Ares, G. (2016), "Does a time constraint modify results from rating-based conjoint analysis? Case study with orange/pomegranate juice bottles", Food Research International, Vol. 90, pp. 244-250.

Rios-Corripio, G. and Guerrero-Beltrán, J.Á. (2019), "Antioxidant and physicochemical characteristics of unfermented and fermented pomegranate (Punica granatum L.) beverages", Journal of Food Science and Technology, Vol. 56 No. 1, pp. 132-139. 
BFJ

122,12

3884
Roininen, K., Lähteenmäki, L. and Tuorila, H. (1999), "Quantification of consumer attitudes to health and hedonic characteristics of foods", Appetite, Vol. 33 No. 1, pp. 71-88.

Roman, S., Sánchez-Siles, L.M. and Siegrist, M. (2017), "The importance of food naturalness for consumers: results of a systematic review", Trends in Food Science and Technology, Vol. 67, pp. 44-57.

Romano, K.R., Dias Bartolomeu Abadio Finco, F., Rosenthal, A., Vinicius Alves Finco, M. and Deliza, R. (2016), "Willingness to pay more for value-added pomegranate juice (Punica granatum L.): an open-ended contingent valuation”, Food Research International, Vol. 89, pp. 359-364.

Sidhu, J.S. and Zafar, T.A. (2012), "Super fruits: pomegranate, wolfberry, aronia (chokeberry), acai, noni, and amla", in Sinha, N.K., Sidhu, J.S., Barta, J., Wu, J.S.B. and Cano, M.P. (Eds), Handbook of Fruits and Fruit Processing, Wiley-Blackwell, Ames, IA, pp. 653-679.

Stover, E. and Mercure, E.W. (2007), "The pomegranate: a new look at the fruit of paradise", HortScience, Vol. 42 No. 5, pp. 1088-1092.

Tallant, A., Rettig, M. and Tennyson, S. (2018), "Barriers and facilitators for fruit and vegetable consumption among adults in rural counties", Family and Consumer Sciences Research Journal, Vol. 47 No. 1, pp. 87-100.

Thienhirun, S. and Chung, S. (2018), "Consumer attitudes and preferences toward cross-cultural readyto-eat (RTE) food", Journal of Food Products Marketing, Vol. 24 No. 1, pp. 56-79.

van den Bogerd, N., Maas, J., Seidell, J.C. and Dijkstra, S.C. (2019), "Fruit and vegetable intakes, associated characteristics and perceptions of current and future availability in Dutch university students”, Public Health Nutrition, Vol. 22 No. 11, pp. 1951-1959.

Verlegh, P.W. and Steenkamp, J.B.E. (1999), "A review and meta-analysis of country-of-origin research”, Journal of Economic Psychology, Vol. 20 No. 5, pp. 521-546.

Zaouay, F., Salem, H., Labidi, R. and Mars, M. (2014), "Development and quality assessment of new drinks combining sweet and sour pomegranate juices", Emirates Journal of Food and Agriculture, Vol. 26 No. 1, pp. 1-8.

\section{Corresponding author}

Samuele Trestini can be contacted at: samuele.trestini@unipd.it

For instructions on how to order reprints of this article, please visit our website:

www.emeraldgrouppublishing.com/licensing/reprints.htm

Or contact us for further details: permissions@emeraldinsight.com 